\title{
Prediction of diabetic foot ulcer healing in type 2 diabetic subjects using routine clinical and laboratory parameters
}

This article was published in the following Dove Press journal:

Research and Reports in Endocrine Disorders

22 March 2016

Number of times this article has been viewed

\author{
Abdullah S AIGoblan' \\ Ibrahim MAlrasheedi ${ }^{2}$ \\ Osman $\mathrm{H}$ Basheir $^{3}$ \\ Khawaja $\mathrm{H} \mathrm{Haider}^{3}$ \\ 'Diabetes Center, ${ }^{2}$ Medical \\ Department, King Fahad Specialist \\ Hospital, Buriadah, Qassim, ${ }^{3}$ Sulaiman \\ AIRajhi Colleges, Al Bukairiyah, \\ Kingdom of Saudi Arabia
}

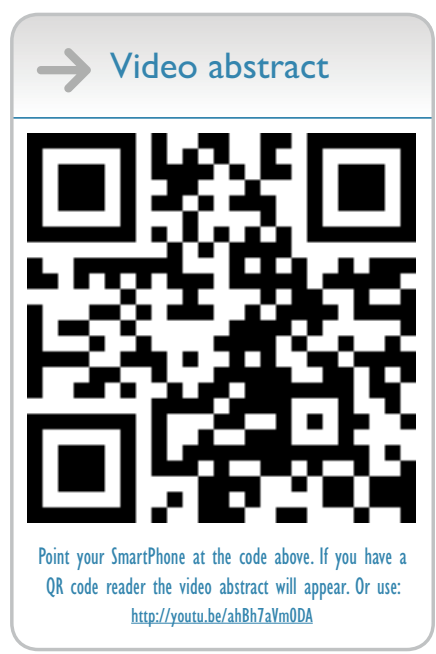

Correspondence: Abdullah S AIGoblan Diabetes Center, King Fahad Specialist Hospital, King khalid Road, Buraidah, Qassim 2259, Kingdom of Saudi Arabia Email agoblan@yahoo.com

\begin{abstract}
Diabetic foot ulcers are associated with substantial morbidity and mortality in diabetic patients. The aim of the study was to assess the validity and effectiveness of body mass index (BMI) and hemoglobin A1c (HbA1c) to predict foot ulcer healing in diabetic patients. We hypothesized that routine clinical and laboratory parameters may reliably predict the healing of diabetic foot ulcers. To validate this hypothesis, a single-center analytical study was carried out in 140 diabetic patients with foot ulceration (from February 2014 to February 2015) in Al Qassim region of the Kingdom of Saudi Arabia. The data collection included demographics, medical diagnoses, BMI measures, ulcer healing duration, and $\mathrm{HbA} 1 \mathrm{c}$ results. The results show that $\mathrm{BMI}$ and $\mathrm{HbA} 1 \mathrm{c}$ levels were strongly associated with the process as well as duration of foot ulcer healing in the diabetic patients. Higher BMI and elevated HbAlc were associated with poor prognosis in terms of foot ulcer healing. Future studies with concomitant use of both the predictors would be an interesting strategy.
\end{abstract}

Keywords: diabetic foot ulcer, predictor, body mass index, HbAlc

\section{Introduction}

Typically, diabetic foot syndrome is characterized by foot infection, ulceration, or destruction of deep tissues in association with neurological abnormalities and divergent levels of peripheral vascular insufficiency. Diabetic foot ulcer and infections are associated with substantial morbidity and mortality. An estimated $2.5 \%$ of diabetics develop diabetic foot ulcers each year, and 15\% develop diabetic foot during their life time. ${ }^{1}$ The prevalence of diabetes has doubled during the last decade in the Arab countries and in Saudi Arabia; the percentage of patients with diabetic foot is reported to be $13.5 \%{ }^{2}$ The factors that affect ulcer healing in diabetic patients are generally helpful in optimization of patient management strategy besides their routine application as predictors of the outcome. ${ }^{3}$ Some of these predictors are useful in early identification of diabetic patients with high risk for foot ulcers and hence contribute toward lower rate of extremity amputations. ${ }^{4}$ Although prediction of diabetic foot ulcer healing may contribute toward optimized and individualized management of the patient, there is no single established and a universally accepted predictor to this end.

Hemoglobin A1c (HbA1c), an established marker to monitor blood glucose in diabetic patients, is currently being investigated for its association with ulcer healing. 5 As an elevated $\mathrm{HbA}$ 1c predicts poor prognosis for ulcer healing in patients with diabetes, it has been observed that ulcer healing rate is significantly slower if the HbA1c levels are high. This observation is especially significant in ulcers located on the foot. ${ }^{5}$ 
A study for the pattern and factors associated with glycemic control in Saudi diabetic patients reported that $50 \%$ of the patients with type 2 diabetes had an uncontrolled diabetes (random blood glucose $>10 \mathrm{mmol} / \mathrm{L}) .{ }^{6}$ On the same note, obesity was associated with a multitude of complications including impairment of cutaneous wound healing, fascial dehiscence, and total wound failure. The prime objective of our study was to determine the significance of body mass index (BMI) and HbA1c level as predictors of prognosis in patients with diabetic foot ulcers.

\section{Patients and methods}

A prospective analytical study was carried out in diabetic patients with foot ulceration $(n=140)$ to determine the role of various factors affecting the ulcer healing process. Ethical approval was obtained from the Regional Research Ethics Committee, General Directorate of Health Affairs, Al Qassim Region, Ministry of Health, Kingdom of Saudi Arabia. The participants were recruited from the Diabetic Clinic, King Fahad Specialist Diabetes Center, Buriadah, Qassim, Kingdom of Saudi Arabia, during 12-month period from February 2014 to February 2015. Informed consent was obtained from the patients. As a part of the inclusion criteria, all patients with foot ulcers, ischemic, neuropathic, or neuro-ischemic ulcers were included, whereas patients with nondiabetic foot ulcers were excluded from the study. The data collection included demographics, medical diagnoses, BMI measures, HgbA1c levels, and ulcer healing results. We employed our standard management protocol in the diabetic center for management of the foot ulcer patients. As a part of this management protocol, all patients underwent a regular wound debridement and dressing using normal saline and antiseptic. For pressure ulcers and neuropathic ulcers, we aided the treatment intervention with off-loading strategy which primarily involved shoe off-loading. Fiber glass cast was employed in some cases. For patients with ischemic ulcers, vascular management approach such as stenting was used additionally.

For the assessment of ulcer healing for each patient, we photographed his ulcer/s at the time of presentation followed by photographing the healing ulcers at stipulated time points (ie, 2, 3, and 6 months) as a follow-up. The photographs were then used to compare ulcer size, presence of necrotic tissue, and the granulation tissue formation in order to ascertain the progress of healing. ${ }^{5}$ Data analysis was performed using SPSS-20.

\section{Results}

A total of 140 patients (male $n=83,59.3 \%$; female $n=57$, $40.7 \%$ ) were enrolled in the study. Based on the length of the disease, $45 \%$ of the patients had diabetes for $<10$ years, $38.6 \%$ for $10-20$ years, and $16.4 \%$ for $>20$ years. The average age of the patients included in the study was 56 years (standard deviation $[\mathrm{SD}] \pm 9.7$ ).

The mean body weight of the patients was $81 \mathrm{~kg}(\mathrm{STD} \pm 13)$. BMI measurements showed that $12.9 \%$ patients had normal BMI, whereas $30.7 \%$ were overweight and $56.4 \%$ were categorized as obese with $\mathrm{BMI}>30$. None of the patients included in the study had underweight BMI (Table 1).

The course of healing and the duration of healing process showed a significant relationship with BMI in these patients $(P=0.005)$. Whereas $61 \%$ patients with normal BMI showed healed foot ulcers within the first 3 months and $11.1 \%$ healed in $>7$ months, $36.7 \%$ of obese group of patients had delayed healing of the foot ulcers spanning over $>7$ months in contrast to $24 \%$ of them who had healing in $<3$ months (Table 1). A large majority of the patients $(83.3 \%)$ with normal weight showed complete wound healing within 3 months, while $41.8 \%$ of obese patients showed complete healing ( $P=0.022$; Table 2$)$.

Similar observations were also made with $\mathrm{HbA1c}$ as a predictor of foot ulcer healing process. Forty-eight percent

Table I Relationship between BMI and the duration of diabetic foot ulcer healing

\begin{tabular}{|c|c|c|c|c|c|c|c|c|}
\hline & & & \multicolumn{5}{|c|}{ Duration to achieve healed foot ulcers } & \multirow[t]{2}{*}{ Total } \\
\hline & & & $<3$ months & 3-6 months & 7 months-I year & I-2 years & $>2$ years & \\
\hline \multirow[t]{6}{*}{ BMI } & Normal & Number (n) & 11 & 5 & 2 & 0 & 0 & 18 \\
\hline & & $\%$ & 61.1 & 27.8 & II.I & 0 & 0 & 100 \\
\hline & Overweight & Number (n) & 15 & 20 & 8 & 0 & 0 & 43 \\
\hline & & $\%$ & 34.9 & 46.5 & 18.6 & 0 & 0 & 100 \\
\hline & Obese & Number (n) & 19 & 22 & 29 & 7 & 2 & 79 \\
\hline & & $\%$ & 24.1 & 27.8 & 36.7 & 8.9 & 2.5 & 100 \\
\hline \multirow[t]{2}{*}{ Total } & & Number (n) & 45 & 47 & 39 & 7 & 2 & 140 \\
\hline & & $\%$ & 32.1 & 33.6 & 27.9 & 5 & 1.4 & 100 \\
\hline
\end{tabular}

Abbreviation: BMI, body mass index. 
Table 2 Relationship between BMI and the process of diabetic foot ulcer healing.

\begin{tabular}{|c|c|c|c|c|c|c|c|}
\hline & & & \multicolumn{4}{|l|}{ Healing process } & \multirow[t]{2}{*}{ Total } \\
\hline & & & Complete healing & Partial healing & No healing & Healing with graft & \\
\hline \multirow[t]{9}{*}{ BMI } & Normal & Number & 15 & 2 & I & 0 & 18 \\
\hline & & $\%$ & 83.3 & 11.1 & 5.6 & 0 & 100 \\
\hline & & $\%$ of total & 10.7 & 1.4 & 0.7 & 0 & 12.9 \\
\hline & Overweight & Number & 24 & 16 & 2 & $\mathrm{I}$ & 43 \\
\hline & & $\%$ & 55.8 & 37.2 & 4.7 & 2.3 & 100 \\
\hline & & $\%$ of total & 17.1 & 11.4 & 1.4 & 0.7 & 30.7 \\
\hline & Obese & Number & 33 & 28 & II & 7 & 79 \\
\hline & & $\%$ & 41.8 & 35.4 & 13.9 & 8.9 & 100 \\
\hline & & $\%$ of total & 23.6 & 20 & 7.9 & 5 & 56.4 \\
\hline \multirow[t]{2}{*}{ Total } & & Number & 72 & 46 & 14 & 8 & 140 \\
\hline & & $\%$ & 51.4 & 32.9 & 10 & 5.7 & 100 \\
\hline
\end{tabular}

Abbreviation: BMI, body mass index.

of diabetic patients with controlled HbAlc $(<7 \mathrm{mmol} / \mathrm{L})$ had foot ulcer healing within 3 months, $44 \%$ had healing in 3-6 months, and $8 \%$ took $>7$ months for complete healing of the foot ulcers. On the other hand, in patients with uncontrolled diabetes indicated by highly elevated $\mathrm{HbA} 1 \mathrm{c}$ $(>10 \mathrm{mmol} / \mathrm{L})$, a significant delay in foot ulcers was observed in majority of the patients (Tables 3 and 4).

Comparing patients with controlled highly elevated $\mathrm{HbA} 1 \mathrm{c}$, only $23 \%$ of patients had healed foot ulcers within 3 months, $28 \%$ between 3 and 6 months, and $48 \%>7$ months $(P=0.024)$. A similar association was observed between the process of healing and $\mathrm{HbA} 1 \mathrm{c}$ levels in our patients. While studying the healing process in relation to $\mathrm{HbAlc}$ levels, we observed that $68 \%$ of patients with normal $\mathrm{HbAlc}$ had completely healed foot ulcers, whereas $20 \%$ showed partial healing and $4 \%$ had uncured foot ulcers (Table 4 ). The remaining $8 \%$ of patients required graft placement. Among the patients with high $\mathrm{HbA1}$ c, $45.9 \%$ showed complete healing, whereas $33.8 \%$ had partial healing, $5.4 \%$ progressed to grafting process, and $14.9 \%$ had unhealed foot ulcers.

An interesting feature of our results was that both BMI and $\mathrm{HbA} 1 \mathrm{c}$ are equally reliable predictors of foot ulcers in diabetic patients. A direct comparison of the foot ulcer healing time duration (Tables 1 and 3) as well as completion of healing (Tables 2 and 4) was made with BMI and $\mathrm{HbA1c}$.

\section{Discussion}

Typically, diabetic foot syndrome is characterized by foot infection, ulceration, or destruction of deep tissues in association with neurological abnormalities and divergent levels of peripheral vascular insufficiency. Despite in-depth studies of the risk factors associated with diabetic foot ulcer development and the seriousness of the pathological consequences that may culminate into limb amputation and fatality, there is no standard criterion yet established to predict the prognosis of diabetic foot ulcer healing. Ours is one of the many studies in the Kingdom of Saudi Arabia that reports increased prevalence of problems associated with diabetic foot syndrome and searches for a predictor that would be helpful in predicting the prognosis at the end of the treatment. ${ }^{6,7} \mathrm{In}$ line with our main hypothesis that various baseline clinical parameters can be exploited as predictors of prognosis for diabetic foot ulcers healing, we have studied the feasibility and effectiveness of BMI and $\mathrm{HbAlc}$ in this regard. The main findings of the study are that both BMI, as an index of

Table 3 Association of $\mathrm{HbAlc}$ and healing time duration

\begin{tabular}{|c|c|c|c|c|c|c|c|c|}
\hline & & & \multicolumn{5}{|c|}{ Duration to achieve healed foot ulcer } & \multirow[t]{2}{*}{ Total } \\
\hline & & & $<3$ months & 3-6 months & 7 months-I year & $\mathrm{I}-2$ years & $>2$ years & \\
\hline \multirow[t]{6}{*}{$\mathrm{HbAlc}$} & Normal & Number & 12 & 11 & 1 & 1 & 0 & 25 \\
\hline & & $\%$ & 48 & 44 & 4 & 4 & 0 & 100 \\
\hline & Mildly elevated & Number & 16 & 15 & 9 & 1 & 0 & 41 \\
\hline & & $\%$ & 39 & 36.6 & 22 & 2.4 & 0 & 100 \\
\hline & Highly elevated & Number & 17 & 21 & 29 & 5 & 2 & 74 \\
\hline & & $\%$ & 23 & 28.4 & 39.2 & 6.8 & 2.7 & 100 \\
\hline \multirow[t]{2}{*}{ Total } & & Number & 45 & 47 & 39 & 7 & 2 & 140 \\
\hline & & $\%$ & 32.1 & 33.6 & 27.9 & 5 & $\mathrm{I} .4$ & 100 \\
\hline
\end{tabular}

Abbreviation: HbAlc, hemoglobin Alc. 
Table 4 Association between HbAlc levels and the process of diabetic foot ulcer healing

\begin{tabular}{|c|c|c|c|c|c|c|c|}
\hline & & & \multicolumn{4}{|l|}{ Healing process } & \multirow[t]{2}{*}{ Total } \\
\hline & & & Complete healing & Partial healing & No healing & Healing with graft & \\
\hline \multirow[t]{9}{*}{$\mathrm{HbAlc}$} & Normal & Number & 17 & 5 & $\mathrm{I}$ & 2 & 25 \\
\hline & & $\%$ & 68 & 20 & 4 & 8 & 100 \\
\hline & & $\%$ of total & 12.1 & 3.6 & 0.7 & 1.4 & 17.9 \\
\hline & Mildly elevated & Number & 21 & 16 & 2 & 2 & 41 \\
\hline & & $\%$ & 51.2 & 39 & 4.9 & 4.9 & 100 \\
\hline & & $\%$ of total & 15 & 11.4 & 1.4 & 1.4 & 29.3 \\
\hline & Highly elevated & Number & 34 & 25 & 11 & 4 & 74 \\
\hline & & $\%$ & 45.9 & 33.8 & 14.9 & 5.4 & 100 \\
\hline & & $\%$ of total & 24.3 & 17.9 & 7.9 & 2.9 & 52.9 \\
\hline \multirow[t]{2}{*}{ Total } & & Number & 72 & 46 & 14 & 8 & 140 \\
\hline & & $\%$ of total & 51.4 & 32.9 & 10 & 5.7 & 100 \\
\hline
\end{tabular}

Abbreviation: $\mathrm{HbAlc}$, hemoglobin Alc.

weight for height, and $\mathrm{HbA1c}$, as an indicator of glycemic control in the body, show significant association with foot ulcer healing and therefore can be used as reliable predictors of diabetic foot ulcer prognosis.

Multiple risk factors have been studied to discriminate between healing and nonhealing ulcers by standard therapeutic intervention. ${ }^{8}$ Of these, modifiable factors including $\mathrm{BMI}$ and $\mathrm{HbA} 1 \mathrm{c}$ have gained special attention of researchers and have been extensively studied in relation with diabetic foot ulcers, gangrene, and limb amputation. ${ }^{9} \mathrm{BMI}$ is closely linked with obesity and type 2 diabetes mellitus. In fact, obesity is accounted for as one of the higher risk factors for diabetes. ${ }^{6,10}$ We observed that $87.1 \%$ of the patients in our study were either overweight or obese as compared to only $12.9 \%$ with normal weight, while none of our patients was underweight. Increased incidence of foot ulcers in diabetic patients with raised BMI is generally observed. ${ }^{11}$ Keeping all other factors constant, overweight diabetic patients having BMI of $24.5-29.5 \mathrm{~kg} / \mathrm{m}^{2}$ are at four times higher risk than diabetic patients with normal BMI $\left(16.5-24.5 \mathrm{~kg} / \mathrm{m}^{2}\right){ }^{12}$ We observed that the healing process of foot ulcers in the patients included in the study had a significant association with these changes in weight. We observed complete healing of the ulcer within the first 3 months in $61 \%$ of patients with normal weight, while $49 \%$ of the obese patients had complete healing in 7 months. These observations clearly showed that healing of foot ulcers in the diabetic patients was delayed in obese patients. Although we did not look for the underlying mechanism of the delayed healing of ulcers, it may be related to obesity in various ways such as increased risk of infection and the relatively insufficient nutritive blood supply of the adipose tissue. ${ }^{13}$ Moreover, reduced oxygen tension might lead to decrease in collagen synthesis and the ability to support the important mechanisms of healing process. ${ }^{14}$ Increase in weight can also affect the foot ulcer by increasing the pressure on the foot. ${ }^{15}$ Pinzur et al found strong association between diabetes-associated foot morbidity and morbid obesity. ${ }^{16}$

Various studies have attempted to establish a relationship between blood glucose levels and wound healing albeit with limited understanding of the underlying molecular mechanism. It is generally considered that a persistently elevated glucose level due to compromised glycemic control in the body results in impaired oxygen and nutrient supply to the ulcer area and a concomitantly compromised immune response due to impaired chemotaxis and phagocytosis. Given that glycated hemoglobin $\mathrm{HbA} 1 \mathrm{c}$ is a reliable marker of glycemic control spanning over the previous 2-3 months, ${ }^{17}$ it is now being recommended by the American Diabetes Association and World Health Organization as a reliable marker for diagnosis of diabetes. A validated relationship has also been established between HbAlc levels and various pathological complications in diabetic patients such as diabetic retinopathy and foot ulcers. ${ }^{18,19}$ However, there are conflicting data published regarding HbAlc levels as a determinant of ulcer healing process. A prospective study involving 314 diabetic patients with foot ulcers showed a significant association between various clinical risk factors and the healing process but with little evidence of association with short-term metabolic control assessed by $\mathrm{HbAlc}$ analysis. ${ }^{20}$ On the contrary, more recent studies contradict this observation and report not only that there is a significant association of $\mathrm{HbAl} \mathrm{c}$ with foot ulcer development but also that $\mathrm{HbA} 1 \mathrm{c}$ is a reliable predictor of foot ulcer healing. 5.18 A retrospective cohort study involving 183 diabetic patients (average age 61 years) showed that $\mathrm{HbA} 1 \mathrm{c}$ was significantly associated with ulcer-area healing rate and was a superior biomarker to predict ulcer-area healing rate as compared 
to all the other measures assessed during the study. ${ }^{5}$ It was observed that for every $1 \%$ increase in $\mathrm{HbA} 1 \mathrm{c}$ levels, the rate of ulcer-area healing decreased by $0.028 \mathrm{~cm}^{2} /$ day. Another clinical study has reported similar findings implying $\mathrm{HbA} 1 \mathrm{c}$ as a significant determinant of foot ulcer healing in diabetic patients. ${ }^{21}$ The healing time for foot ulcers in patients with lower $\mathrm{HbA1c}$ was shorter than patients with higher values. Although foot ulcer healing has also been reported in patients with higher $\mathrm{HbA1c}$, the healing time was significantly longer. Our study results were in concordance with these data and showed a significant association between controlled glycemia and the ulcer healing. We observed that patients with lower $\mathrm{HbA1c}$ had shorter healing duration compared with patients with higher level of HbA1c. Despite clinically relevant and significant observations, our study was limited by its nature and small number of the patients and subgroups of patients included in the study. Moreover, we did not measure the body weight and $\mathrm{HbA} 1 \mathrm{c}$ regularly at all the stipulated time points.

In conclusion, our study results show that both BMI and $\mathrm{HbA1c}$ show good association with the process of healing as well as time required for healing process to complete. Both higher $\mathrm{BMI}$ and elevated $\mathrm{HbA} 1 \mathrm{c}$ were associated with slower and incomplete healing of foot ulcers in diabetic patients. Given their reliability as tools to diagnose and monitor diabetes and its related complications, both parameters can be used as dependable predictors of foot ulcer healing in the diabetic patients. Further studies with larger number of subjects and a combinatorial approach involving the simultaneous use of both the parameters as predictors would be an interesting strategy to develop clinically reliable prediction method of prognosis in patients with diabetic foot ulcers.

\section{Disclosure}

The authors report no conflicts of interest in this work.

\section{References}

1. Assaad-Khalil SH, Zaki A, Abdel Rehim A, et al. Prevalence of diabetic foot disorders and related risk factors among Egyptian subjects with diabetes. Primary Care Diabetes. 2015;9(4):297-303.

2. Al-Wakeel JS, Hammad D, Al Suwaida A, Mitwalli AH, Memon NA, Sulimani F. Microvascular and macrovascular complications in diabetic nephropathy patients referred to nephrology clinic. Saudi Journal of Kidney Diseases and Transplantation: An Official Publication of the Saudi Center for Organ Transplantation, Saudi Arabia. 2009;20(1):77-85.
3. Elsharawy MA, Hassan K, Alawad N, Kredees A, Almulhim A. Screening of diabetic foot in surgical inpatients: a hospital-based study in Saudi Arabia. The International Journal of Angiology: Official Publication of the International College of Angiology, Inc. 2012;21(4):213-216.

4. Abolfotouh MA, Alfaifi SA, Al-Gannas AS. Risk factors of diabetic foot in central Saudi Arabia. Saudi Medical Journal. 2011;32(7):708-713.

5. Christman AL, Selvin E, Margolis DJ, Lazarus GS, Garza LA. Hemoglobin A1c predicts healing rate in diabetic wounds. The Journal of Investigative Dermatology. 2011;131(10):2121-2127.

6. Ahmed AA. Epidemiology of diabetes mellitus and diabetic foot problems in Saudi Arabia. Avances en Diabetologia. 2010;29:29-35.

7. Sulimani RA, Famuyiwa OO, Mekki MO. Pattern of diabetic foot lesions in Saudi Arabia: experience from King Khalid University Hospital, Riyadh. Annals of Saudi Medicine. 1991;11(1):47-50.

8. Margolis DJ, Allen-Taylor L, Hoffstad O, Berlin JA. Diabetic neuropathic foot ulcers: the association of wound size, wound duration, and wound grade on healing. Diabetes Care. 2002;25(10):1835-1839.

9. Al-Rubeaan K, Al Derwish M, Ouizi S, et al. Diabetic foot complications and their risk factors from a large retrospective cohort study. PLoS One. 2015;10(5):e0124446.

10. Mansour M, Al-Nozha YYA-M, Mohammed A, et al. Obesity in Saudi Arabia. Saudi Medical Journal. 2005;26(5):824-829.

11. Sohn MW, Budiman-Mak E, Lee TA, Oh E, Stuck RM. Significant J-shaped association between body mass index (BMI) and diabetic foot ulcers. Diabetes/Metabolism Research and Reviews. 2011;27(4):402-409.

12. Deribe B, Woldemichael K, Nemera G. Prevalence and factors influencing diabetic foot ulcer among diabetic patients attending Arbaminch Hospital, South Ethiopia. Journal of Diabetes and Metabolism. 2014;2:322.

13. Mousley M. Diabetes and its effect on wound healing and patient care. Nursing Times. 2003;99(42):70.

14. Pierpont YN, Dinh TP, Emerick Salas R, et al. Obesity and surgical wound healing: a current review. International Scholarly Research Notices Obesity. 2014;2014:13.

15. Vela SA, Lavery LA, Armstrong DG, Anaim AA. The effect of increased weight on peak pressures: implications for obesity and diabetic foot pathology. The Journal of Foot and Ankle Surgery. 1998;37(3):416-420.

16. Pinzur M, Freeland R, Juknelis D. The association between body mass index and foot disorders in diabetic patients. Foot and Ankle International. 2005;26(5):375-377.

17. WHO guidelines approved by the Guidelines Review Committee. Use of glycated haemoglobin (HbA1c) in the diagnosis of diabetes mellitus: abbreviated report of a WHO consultation. Geneva: World Health Organization; 2011.

18. Zubair M, Malik A, Ahmad J. Glycosylated hemoglobin in diabetic foot and its correlation with clinical variables in a north Indian tertiary care hospital. Journal of Diabetes and Metabolism. 2015;6:7.

19. Shahbazian H, Yazdanpanah L, Latifi SM. Risk assessment of patients with diabetes for foot ulcers according to risk classification consensus of International Working Group on Diabetic Foot (IWGDF). Pakistan Journal of Medical Sciences. 2013;29(3):730-734.

20. Apelqvist J, Agardh CD. The association between clinical risk factors and outcome of diabetic foot ulcers. Diabetes Research and Clinical Practice. 1992;18(1):43-53.

21. Markuson M, Hanson D, Anderson J, et al. The relationship between hemoglobin $\mathrm{A}(1 \mathrm{c})$ values and healing time for lower extremity ulcers in individuals with diabetes. Advances in Skin and Wound Care. 2009;22(8):365-372. 
Research and Reports in Endocrine Disorders

Dovepress

\section{Publish your work in this journal}

Research and Reports in Endocrine Disorders is an international, peerreviewed, open access journal publishing original research, reports, reviews and commentaries on all areas of endocrinology, endocrine disorders and therapeutic interventions. The manuscript management system is completely online and includes a very quick and fair to read real quotes from published authors.

Submit your manuscript here: http://www.dovepress.com/research-and-reports-in-endocrine-disorders-journal 